\title{
Household, maternal, and child related determinants of hemoglobin levels of Ethiopian children: hierarchical regression analysis
}

Shimels Hussien Mohammed ${ }^{1 *}$ (D) Tesfa Dejenie Habtewold ${ }^{2}$ and Ahmad Esmaillzadeh $3,4,5$

\begin{abstract}
Background: Anemia remains a major public health problem among children under five years old in Ethiopia, rising unexpectedly from 44\% national prevalence in 2011 to 57\% in 2016. In this study, we investigated the household, maternal and child-related dietary and non-dietary factors associated with hemoglobin $(\mathrm{Hb})$ level of infants and young children.
\end{abstract}

Method: We analyzed data from a nationally representative sample of 2902 children aged 6-23 months, included in the 2016 Ethiopian demographic and health survey (EDHS). Hierarchical linear regression analysis was done to identify the factors associated with $\mathrm{Hb}$ level. We reported adjusted $\beta$ (aß) with 95\% confidence interval (Cl).

Result: Overall, $72 \%$ of children under 2 years of age were anemic in Ethiopia in 2016. Household factors: rich household wealth category $(\mathrm{a} \beta=0.48,95 \% \mathrm{Cl}=0.33-0.63, P<0.001)$, and agrarian regions $(\mathrm{a} \beta=0.64,95 \% \mathrm{Cl}=0.40-0$. $88, P<0.001$ ) were significantly associated with a higher mean $\mathrm{Hb}$ level. Maternal factors: secondary and above education level $(a \beta=0.69,95 \% C l=0.23-1.16, P=0.004)$, and being not anemic $(a \beta=0.40,95 \% C l=0.26-0.53, P<0$. $001)$ were significantly associated with a higher mean $\mathrm{Hb}$ level. Child factors: age below 12 months $(a \beta=0.72$, $95 \% \mathrm{Cl}=0.57-0.88, P<0.001)$, female sex $(a \beta=0.16,95 \% \mathrm{Cl}=0.03-0.30, P=0.019)$, being not underweight $(a \beta=0.22$, $95 \% \mathrm{Cl}=0.02-0.42, P=0.031)$, average birth size $(\mathrm{a} \beta=0.25,95 \% \mathrm{Cl}=0.08-0.42, P=0.003)$, no history of recent infection $(a \beta=0.18,95 \% \mathrm{Cl}=0.02-0.33, P=0.025)$, currently breastfeeding $(a \beta=0.28,95 \% \mathrm{Cl}=0.12-0.44, P=0.002)$, vitamin $A$ supplementation $(a \beta=0.17,95 \% \mathrm{Cl}=0.06-0.28, P=0.021)$, and frequent meal feeding $(a \beta=0.11,95 \% \mathrm{Cl}=0$. $05-0.16, P=0.034$ ) were significantly associated with a higher mean $\mathrm{Hb}$ level.

Conclusion: $\mathrm{Hb}$ level was associated with various dietary and non-dietary influences originating from household, maternal, and child levels. A comprehensive approach, addressing the multi-factorial nature of $\mathrm{Hb}$ status, might stand an important consideration to reverse the recent rise in anemia prevalence in Ethiopia.

Keywords: Hemoglobin status, Anemia, Risk factors, Children

\footnotetext{
* Correspondence: shimelsh@gmail.com

${ }^{1}$ Department of Community Nutrition, School of Nutritional Sciences and

Dietetics, Tehran University of Medical Sciences-International Campus,

Tehran, Iran

Full list of author information is available at the end of the article
}

C The Author(s). 2019 Open Access This article is distributed under the terms of the Creative Commons Attribution 4.0 International License (http://creativecommons.org/licenses/by/4.0/), which permits unrestricted use, distribution, and reproduction in any medium, provided you give appropriate credit to the original author(s) and the source, provide a link to the Creative Commons license, and indicate if changes were made. The Creative Commons Public Domain Dedication waiver (http://creativecommons.org/publicdomain/zero/1.0/) applies to the data made available in this article, unless otherwise stated. 


\section{Background}

Anemia, marked by a low hemoglobin $(\mathrm{Hb})$ level, continues to be a significant public health concern affecting almost a third of the world's population. Infants and young children are of particular concern, developing anemia at a higher rate and bearing the highest burden [1]. In 2016, anemia prevalence among children under five years old in Ethiopia was 57\%, rising unexpectedly from $44 \%$ in 2011 [2]. Infants and young children bear the highest burden of anemia in Ethiopia, with a $72 \%$ prevalence of anemia among those under two years of age [2]. The World Health Organization (WHO) classifies anemia prevalence above $40 \%$ as a severe public health problem [3].

Anemia is a multi-causal problem with a number of dietary and non-dietary risk factors [1, 4]. Food items with high phytate and polyphenol contents are associated with a high risk of anemia. Inadequate dietary or supplemental intake of iron, folate, and vitamin A often leads to anemia [4, 5]. While iron deficiency has long been considered the single greatest factor contributing to anemia, accounting for almost $50 \%$ of anemia globally $[4,5]$, recent reports suggest that iron deficiency is not as significant a culprit as was once thought [6]. Its contribution is particularly low in countries with high anemia and inflammation burdens, where it is estimated to account for 14 and $20 \%$ of the burden of anemia among preschool children, respectively [6]. Intestinal parasites, malaria, and infection are also among the main immediate causes of anemia, particularly in developing countries $[4,6]$. Chronic illness or inflammatory conditions increase expression of hepcidin hormone, which reduces the absorption of iron by enterocytes and its exportation by ferroportin, thereby increasing the risk of anemia [7]. The main underlying conditions leading to anemia in developing countries are suboptimal feeding, caring and hygiene practices, coupled with poor health care. Poor socioeconomic status is one of the basic determinants of anemia [5, 8, 9].

Reducing the burden of anemia is one of the six global nutrition targets outlined by the WHO for the period 2012-2025 [10]. In Ethiopia, some interventions have been put in place to address the burden of anemia. These include distribution and promotion of the use of insecticide-treated mosquito nets, deworming and iron supplementation, and school- and community-based nutrition interventions [11]. While some studies are available on the determinants of anemia or $\mathrm{Hb}$ level in Ethiopia, most studies did not account for the hierarchical nature and interrelationships among the multilevel determinants [12, 13]. Their estimates were mainly based on single model regression analyses, which could be problematic. For example, the distal determinants of $\mathrm{Hb}$ level, like community and household factors, influence not only $\mathrm{Hb}$ level directly but also its underlying and proximal determinants like breastfeeding and dietary practices. Thus, including all variables in one model, a practice in most of the existing studies, may nullify or weaken the relation of the distal factors with $\mathrm{Hb}$ level [14]. Besides, given the recent increase in the prevalence of anemia in Ethiopia [2] and the time-varying nature of the contextual determinants, it stands timely and necessary to further investigate the determinants of $\mathrm{Hb}$ level. We used $\mathrm{Hb}$ level on a continuous scale to avoid the problem of potential statistical power loss due to dichotomization into anemic and non-anemic groups [15]. The use of Hb level on a continuous scale also enables to evaluate the relation of the determinant factors with the full spectrum of $\mathrm{Hb}$ level, not just with the state of anemia. Thus, in this study, we aimed to investigate the various household, maternal, and child-related dietary and non-dietary factors influencing $\mathrm{Hb}$ level of Ethiopian children aged 6-23 months using the latest nationally representative demographic and health survey, EDHS 2016.

\section{Methods}

Data source, study setting, and population

We used the dataset of children included in the EDHS 2016. EDHS is part of the international demographic and health survey (DHS) program, led by the United States Agency for International Development (USAID), in collaboration with other organizations and host countries [16]. In Ethiopia, the DHS has been conducted every five years since 2000. The latest survey was conducted in 2016 [2]. The full data set of EDHS 2016 is available and accessible on the DHS program website: http://dhsprogram.com/data/dataset/Ethiopia_StandardDHS_2016.cfm. The survey was designed to be representative at both national and regional levels [2]. Children 6-23 months of age, with $\mathrm{Hb}$ level record, were included in this work.

\section{Sample size and sampling methodology}

EDHS 2016 followed a stratified, two-stage cluster design in sample selection. Census enumeration areas (EAs) were the primary sampling units. The sample included 645 EAs, 202 urban and 443 rural EAs. The secondary sampling units were households. In the second stage of sampling, a fixed number of 28 households were selected from each cluster (EAs), by systematic random sampling. All children in the selected households were included and data were collected on various health and nutrition variables, including $\mathrm{Hb}$ level measurement for children aged 6 to 59 months. More information about the methodology of EDHS 2016 can be found in the report of the main findings of the survey [2]. As our interest in this work was on infants and young children, we extracted the data set 
of only those children aged 6-23 months. We found a total of 3105 children aged 6-23 months. Of these, 430 children with no complete record were excluded from the final dataset. The remaining 2675 children were weighted by their corresponding regional sampling weights, providing a final weighted sample size of 2902 children (Fig. 1).

\section{Variables and measurements}

\section{Outcome variable}

The main outcome variable was $\mathrm{Hb}$ level $(\mathrm{g} / \mathrm{dL})$, which is a reliable indicator of anemia at the population level [3]. Blood samples for $\mathrm{Hb}$ test were drawn from a finger or a heel prick. The Hb level was determined by battery operated HemoCue ${ }^{\oplus} 201$ analyzers (Sweden) [2]. Then, the $\mathrm{Hb}$ measures were adjusted for the altitude of the house of the child. In this analysis, Hb level was used on a continuous scale for better statistical power [15] and as it enables evaluating the relation of the determinants with the full spectrum of $\mathrm{Hb}$ level, not just with the state of anemia.

\section{Explanatory variables}

The selection of the explanatory factors was guided by the literature and availability of the variable in the dataset. The variables were categorized into three groups: household, maternal, and child factors.

Household factors: place of residence (urban, rural), region ('mainly agrarian': and 'mainly pastoral'), household wealth category (poor, middle, rich), drinking water sources (improved, unimproved), and toilet facility (improved, unimproved). The household wealth index was calculated by principal component analysis using asset variables collected by the survey and then categorized into tertiles: poor, middle, and rich. Improved sources of drinking water included piped water, bottled water, and protected wells in the compound. Unprotected wells,

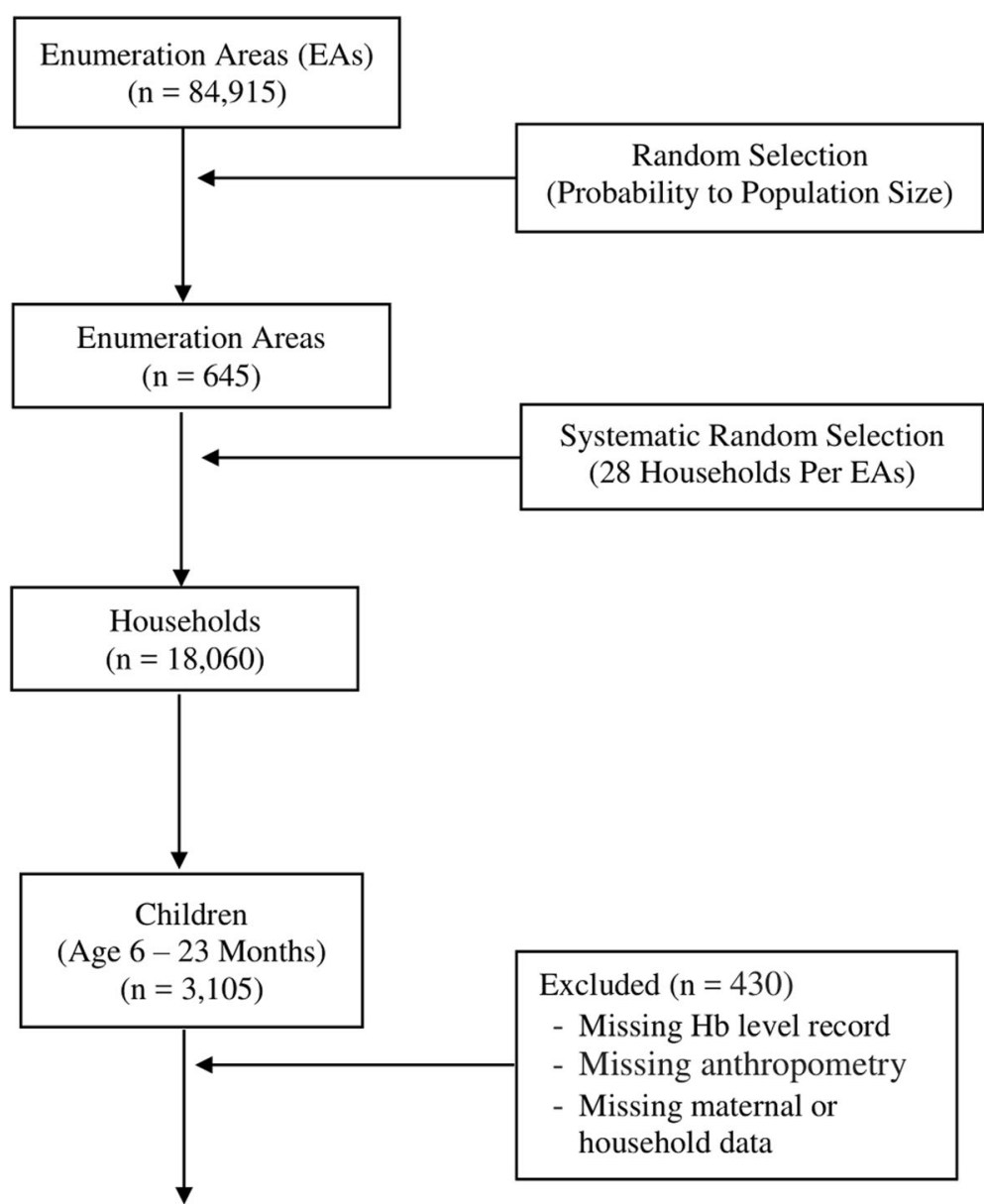

Final Sample

(Unweighted $n=2,675$ )

(Weighted $n=2,902$ )

Fig. 1 Flow chart of sample selection 
springs, rivers, ponds, lakes, and dams were grouped as unimproved water sources. Improved household toilet facilities included flush toilets and ventilated pit latrines. Unimproved household toilet facilities were traditional pit latrines.

Maternal factors: body mass index (BMI) $(<18.5, \geq$ $18.5 \mathrm{~kg} / \mathrm{m}^{2}$ ), anemia status (anemic, not anemic), education status as defined by the highest education level completed (illiterate/none, primary, secondary+), and antenatal care visits (ANC). ANC visits refer to the number of health facility visits the mother attended during the pregnancy of the indexed child and categorized into two groups $(<4,4+$ visits $)$.

Child factors: sex (boy, girl), age ( $<12,12-23$ months), birth size (as reported subjectively by the mother of the child, grouped into three categories: large, average, small); and other anthropometry, health, and dietary practice indicators. According to the WHO 2006 criteria [17], Z-score less than -2 standard deviations (SD) was used to classify children's nutritional status into stunted (low height-for-age), underweight (low weight-for-age), and wasting (low weight-for-height). History of infection (yes, no) was measured by subjective reporting of the mother or caregiver of the child on whether the child had fever, diarrhea, or cough in the last two weeks preceding the survey. Current breastfeeding status (yes, no), early initiation of breastfeeding within the first one hour after birth (yes, no), deworming in the last six months preceding the survey (yes, no), vitamin A supplement use in the last six months preceding the survey (yes, no), iron supplement use in the last seven days preceding the survey (yes, no), and complementary feeding practices (dietary diversity and meal frequency) were also included. Dietary diversity and meal frequency scores were developed based on the $24 \mathrm{~h}$ dietary recall data, which were further categorized into seven food groups: (1) meat, (2) eggs, (3) dairy products, (4) grains, roots, and tubers, (5) legumes and nuts, (6) vitamin-A rich fruits and vegetables, and (7) other fruits and vegetables. According to the WHO criteria, minimum dietary diversity (MDD) is fed from four or more of the above seven food groups and minimum meal frequency (MMF) is met when a child is fed at least three times a day for breastfeeding children and four times a day for non-breastfeeding children [18].

\section{Statistical analysis}

The analysis was done taking into account the complex design of the survey; such that the estimates provided were done based on the weighted data and taking into account the cluster design of the study. Sample weights were applied to compensate for the unequal probability of selection of study participants by region of residence. Small regions were oversampled to ensure data representativeness at regional levels. Thus, following the DHS methodology, sample weights were applied to ensure the data resemble the national population distribution. A detailed explanation of the sampling weighting procedures can be found in the EDHS 2016 report [2]. Bivariable analyses were done to evaluate the relation of each explanatory variable with $\mathrm{Hb}$ level. Variables with $P<0.25$ in the bivariable analyses were included in the final three-stage hierarchical regression analyses, which took into account the relationship among the determinant variables. Thus, three models were constructed, following the approach recommended by Victoria et al. [14]. Statistical significance $(P \leq 0.05)$ of a variable during the hierarchical linear regression analyses was determined at the corresponding model in which the variable of interest was first entered, irrespective its performance in the subsequent model(s). This approach was aimed to avoid the possibility that intermediate variables affect the relation of the distal variables with the outcome variable ( $\mathrm{Hb}$ level). All data analyses were conducted using STATA version 15, and running "svyset cluster [pw=weight]" command before all analyses.

\section{Result}

In this work, we included a total of 2902 children aged 6-23 months, of which 1359 (46.83\%) were boys and 1543 (53.17\%) girls. The majority of study participants were from rural areas $(89.22 \%)$. The mean age $( \pm$ SD) was $14.01 \pm 5.02$ months. The majority of children were from middle- and low- income households (67.22\%). The mean $\mathrm{Hb}$ level $( \pm \mathrm{SD})$ was $10.00 \pm 1.63 \mathrm{~g} / \mathrm{dL}$. The overall prevalence of anemia $(\mathrm{Hb}$ level $<11 \mathrm{~g} / \mathrm{dL})$ among the study population was $71.92 \%$.

Table 1 shows the results of the bivariable analyses of the relation of the household and the maternal factors with $\mathrm{Hb}$ level. The household-related factors found significantly associated with a higher mean $\mathrm{Hb}$ level were living in urban areas, agrarian regions, and households of high wealth category and improved water supply. Among the maternal characteristics, age, anemia status, education level, and ANC visits were significantly associated with $\mathrm{Hb}$ level $(P<0.05)$. Toilet facility and maternal BMI were not significantly associated with $\mathrm{Hb}$ level during the bivariate analyses $(P>0.05)$.

The results of the bivariable analyses of the relationship of the dietary and non-dietary child-related factors with $\mathrm{Hb}$ level are shown in Table 2. The child factors found significantly associated with $\mathrm{Hb}$ level $(P<0.05)$ were sex, age, birth size, height-for-age, weight-for-height, weight-for-age, history of infection, and current breastfeeding status. Early initiation of breastfeeding, deworming medication use in the last six months, iron supplement use in the last seven days, sex, size at birth, MDD, and MMF were not found significantly associated with $\mathrm{Hb}$ level $(P>0.05)$. These 
Table 1 Bivariable analyses of the relation of household and maternal factors with Hb level $(\mathrm{g} / \mathrm{dL})(n=2902)$

\begin{tabular}{|c|c|c|c|c|}
\hline Variables & & Weighted Frequency (\%) & Mean $\mathrm{Hb}(95 \% \mathrm{Cl})$ & $P^{a}$ \\
\hline \multirow[t]{2}{*}{ Residence place } & Urban & 10.78 & $10.35(10.18,10.51)$ & $<0.001$ \\
\hline & Rural & 89.22 & $9.95(9.89,10.02)$ & \\
\hline \multirow[t]{2}{*}{ Region (state) } & Pastoral & 6.56 & $9.29(9.05,9.53)$ & $<0.001$ \\
\hline & Agrarian & 93.44 & $10.05(9.99,10.11)$ & \\
\hline \multirow[t]{3}{*}{ Wealth category } & Poor & 44.16 & $9.69(9.60,9.79)$ & $<0.001$ \\
\hline & Middle & 23.06 & $10.18(10.07,10.28)$ & \\
\hline & Rich & 32.78 & $10.28(10.18,10.38)$ & \\
\hline \multirow[t]{2}{*}{ Toilet facility } & Not improved & 91.40 & $9.99(9.93,10.05)$ & 0.607 \\
\hline & Improved & 8.60 & $10.05(9.85,10.25)$ & \\
\hline \multirow[t]{2}{*}{ Water source } & Not improved & 43.39 & $9.88(9.79,9.97)$ & 0.001 \\
\hline & Improved & 56.61 & $10.08(10.01,10.16)$ & \\
\hline \multirow[t]{2}{*}{ Maternal BMI $\left(\mathrm{kg} / \mathrm{m}^{2}\right)$} & $<18.5$ & 76.01 & $10.03(9.96,10.10)$ & 0.120 \\
\hline & $\geq 18.5$ & 23.99 & $9.92(9.80,10.03)$ & \\
\hline \multirow[t]{2}{*}{ Maternal anemia } & Not anemic & 69.62 & $10.16(10.09,10.23)$ & $<0.001$ \\
\hline & Anemic & 30.38 & $9.63(9.52,9.74)$ & \\
\hline \multirow[t]{3}{*}{ Education level } & Illiterate & 61.26 & $9.91(9.83,9.99)$ & $<0.001$ \\
\hline & Primary & 31.24 & $10.03(9.93,10.13)$ & \\
\hline & Secondary+ & 7.40 & $10.52(10.26,10.78)$ & \\
\hline \multirow[t]{2}{*}{ Antenatal care visits } & $<4$ & 65.94 & $9.93(9.84,9.99)$ & 0.003 \\
\hline & $4+$ & 34.06 & $10.11(10.01,10.21)$ & \\
\hline
\end{tabular}

${ }^{a}$ Independent t-test or one-way ANOVA

estimates were, however, crude and less informative, i.e. not adjusted for any covariate factor.

The results of the hierarchical linear regression analyses between the predictor variables and $\mathrm{Hb}$ level are shown in Table 3. Residence in agrarian regions was associated with a significantly higher mean $\mathrm{Hb}$ level ( $\mathrm{a} \beta=0.64,95 \% \mathrm{CI}=0.40-0.88, P<0.001)$, compared with residence in pastoral regions. Compared with children in the poor wealth category, mean $\mathrm{Hb}$ level was significantly higher in those in middle $(a \beta=0.42$, $95 \% \mathrm{CI}=0.27-0.58, \quad P<0.001)$ and rich $(\mathrm{a} \beta=0.48$, $95 \% \mathrm{CI}=0.33-0.63, \quad P<0.001)$ categories. Mean $\mathrm{Hb}$ level was significantly higher in children of mothers with secondary and above education level $(\mathrm{a} \beta=0.69$, $95 \% \mathrm{CI}=0.23-1.16, P=0.004)$, compared with the value of children of illiterate mothers. Compared with children of anemic mothers, $\mathrm{Hb}$ level was significantly higher in children of non-anemic mothers $(\mathrm{a} \beta=0.40$, $95 \% \mathrm{CI}=0.26-0.53, P<0.001$ ).

Being a girl was associated with a significantly higher mean Hb level $(a \beta=0.16,95 \% C I=0.03-0.30, P=0.019)$, compared with being a boy. Mean $\mathrm{Hb}$ level was significantly higher in children under 12 months of age than in those above 12 months of age $(\mathrm{a} \beta=0.72,95 \% \mathrm{CI}=0.57$ $0.88, P<0.001)$. Children born with an average birth size had a significantly higher mean Hb level $(a \beta=0.25$, $95 \% \mathrm{CI}=0.08-0.42, \quad P=0.003)$, compared with those born with small birth size. Mean Hb level was significantly higher in the non-wasted children (weight-for-age $\geq-2) \quad(\mathrm{a} \beta=0.22, \quad 95 \% \mathrm{CI}=0.02-0.42, \quad P=0.031)$ than in the wasted children. Children who had no history of infection in the last two weeks before the survey had a significantly higher mean $\mathrm{Hb}$ level $(\mathrm{a} \beta=0.18$, $95 \% \mathrm{CI}=0.02-0.33, P=0.025$ ). Currently breastfeeding was associated with a significantly higher mean $\mathrm{Hb}$ level $(\mathrm{a} \beta=0.28,95 \% \mathrm{CI}=0.12-0.44, P=0.002)$, compared with not currently breastfeeding. Children who received vitamin A supplementation in the last six months had a significantly higher mean $\mathrm{Hb}$ level $(\mathrm{a} \beta=0.17,95 \% \mathrm{CI}=$ $0.06-0.28, P=0.021$ ), compared to those who did not receive the supplementation.

After adjusting for covariate factors, place of residence, household size, water source, maternal BMI, ANC, height-for-age, weight-for-height, MDD, and iron supplementation in the last six months prior to the survey did not demonstrate significant associations with $\mathrm{Hb}$ level $(P>0.05)$.

\section{Discussion}

This study was aimed to determine the household, maternal and child factors influencing the $\mathrm{Hb}$ level of infants and young children in Ethiopia. We found a high level of anemia. After adjusting for covariates, the household factors found to be associated with $\mathrm{Hb}$ level were 
Table 2 Bivariable analyses of the relation of child factors with Hb level $(\mathrm{g} / \mathrm{dL})(n=2902)$

\begin{tabular}{|c|c|c|c|c|}
\hline Variables & & Weighted frequency (\%) & Mean Hb $(95 \% \mathrm{Cl})$ & $p^{a}$ \\
\hline \multirow[t]{2}{*}{ Child sex } & Boy & 46.83 & $9.91(9.82,10.00)$ & 0.006 \\
\hline & Girl & 53.17 & $10.07(10.00,10.15)$ & \\
\hline \multirow[t]{2}{*}{ Age (months) } & $<12$ & 41.63 & $9.86(9.77,9.95)$ & $<0.001$ \\
\hline & $12-23$ & 58.37 & $10.11(10.03,10.19)$ & \\
\hline \multirow[t]{3}{*}{ Birth size } & Small & 27.56 & $9.69(9.57,9.81)$ & $<0.001$ \\
\hline & Average & 40.84 & $10.14(10.05,10.22)$ & \\
\hline & Large & 31.60 & $10.10(9.99,10.20)$ & \\
\hline \multirow[t]{2}{*}{ Height-for-age } & $<-2$ Z-score & 32.22 & $9.88(9.77,9.98)$ & 0.006 \\
\hline & $\geq-2$ Z-score & 67.78 & $10.05(9.98,10.13)$ & \\
\hline \multirow[t]{2}{*}{ Weight-for-age } & $<-2$ Z-score & 21.00 & $9.62(9.48,9.76)$ & $<0.001$ \\
\hline & $\geq-2$ Z-score & 79.00 & $10.10(10.03,10.16)$ & \\
\hline \multirow[t]{2}{*}{ Weight-for-height } & $<-2$ Z-score & 12.88 & $9.63(9.48,9.78)$ & $<0.001$ \\
\hline & $\geq-2$ Z-score & 87.12 & $10.05(9.99,10.12)$ & \\
\hline \multirow[t]{2}{*}{ Infection history ${ }^{b}$} & No & 74.04 & $10.05(9.98,10.12)$ & 0.001 \\
\hline & Yes & 25.96 & $9.81(9.69,9.94)$ & \\
\hline \multirow{2}{*}{$\begin{array}{l}\text { Current breastfeeding } \\
\text { status }\end{array}$} & No & 10.17 & $9.68(9.53,9.83)$ & $<0.001$ \\
\hline & Yes & 89.83 & $9.99(9.95,10.03)$ & \\
\hline \multirow{2}{*}{$\begin{array}{l}\text { Early breastfeeding } \\
\text { initiation }\end{array}$} & No & 10.89 & $9.92(9.71,10.13)$ & 0.558 \\
\hline & Yes & 89.11 & $9.98(9.91,10.05)$ & \\
\hline \multirow[t]{2}{*}{ Deworming } & No & 90.57 & $9.99(9.93,10.06)$ & 0.388 \\
\hline & Yes & 9.43 & $10.08(9.90,10.26)$ & \\
\hline \multirow[t]{2}{*}{ Vitamin A supplement } & No & 56.35 & $9.96(9.88,10.04)$ & 0.161 \\
\hline & Yes & 43.65 & $10.05(9.95,10.14)$ & \\
\hline \multirow[t]{2}{*}{ Iron Supplement } & No & 91.92 & $10.00(9.94,10.07)$ & 0.362 \\
\hline & Yes & 8.08 & $9.90(9.71,10.10)$ & \\
\hline \multirow[t]{2}{*}{$\mathrm{MDD}^{\mathrm{C}}$} & No & 86.45 & $9.97(9.91,10.04)$ & 0.068 \\
\hline & Yes & 13.55 & $10.14(10.00,10.27)$ & \\
\hline \multirow[t]{2}{*}{$M M F^{d}$} & No & 56.96 & $9.96(9.88,10.04)$ & 0.235 \\
\hline & Yes & 43.04 & $10.03(9.94,10.12)$ & \\
\hline
\end{tabular}

Independent t-test or one-way ANOVA

bInfection defined as (yes, any one of history of cough, diarrhea or fever in the last two weeks preceding the survey)

${ }^{\mathrm{C}} \mathrm{MDD}$ : Minimum dietary diversity (yes) when a child ate from four or more food groups

${ }^{d}$ MMF: Minimum meal frequency (yes) when a child ate at least three and four times a day for breastfeeding and non-breastfeeding children, respectively

region of residence and household wealth category. Maternal education level and anemia status were significantly associated with $\mathrm{Hb}$ level of children. Sex, birth size, weight-for-age, history of infection, and duration of breastfeeding were the child factors found significantly associated with $\mathrm{Hb}$ level.

The high prevalence of anemia we reported was consistent with the report of EDHS 2016, which showed 78, 76,72 , and $66 \%$ of anemia prevalence among $6-8,9-11$, 12-17, and 18-23 months old children, respectively [2]. This study showed a lower mean $\mathrm{Hb}$ in pastoral regions, compared with the agrarian regions. This might be, in part, due to the high prevalence of malaria in pastoral regions of Ethiopia [19]. Malaria is one of the main risk factors of anemia [5]. Besides, pastoral communities depend on animal milk as a main food source. The low bioavailability of iron in milk could also account for the low $\mathrm{Hb}$ level in these communities. Income was a significant and independent predictor of $\mathrm{Hb}$ level. Children of poor households had a lower mean $\mathrm{Hb}$ level, compared with those of rich households. The result was consistent with previous studies that showed a higher risk of anemia in people with low socioeconomic status $[8,10]$ and it could be due to the fact that health-enhancing practices and options are often limited among the poor. Children of anemic mothers were more likely to have a lower mean $\mathrm{Hb}$ level, compared with those of non-anemic mothers. The result was in agreement with 
Table 3 Hierarchical linear regression analysis of the relation of household, maternal, and child-related factors with $\mathrm{Hb}$ level ( $\mathrm{g} / \mathrm{dL}$ ) $(n=2902)$

\begin{tabular}{|c|c|c|c|c|}
\hline Models & Variables & & $\mathrm{a} \beta(95 \% \mathrm{Cl})$ & P \\
\hline \multirow[t]{10}{*}{ Model 1} & \multirow[t]{2}{*}{ Residence } & Rural & Reference & \multirow[t]{2}{*}{0.799} \\
\hline & & Urban & $0.03(-0.20,0.26)$ & \\
\hline & \multirow[t]{2}{*}{ Region } & Pastoral & Reference & \multirow[t]{2}{*}{$<0.001^{*}$} \\
\hline & & Agrarian & $0.64(0.40,0.88)$ & \\
\hline & \multirow[t]{3}{*}{ Wealth category } & Poor & Reference & \\
\hline & & Middle & $0.42(0.27,0.58)$ & $<0.001^{*}$ \\
\hline & & Rich & $0.48(0.33,0.63)$ & $<0.001^{*}$ \\
\hline & \multirow[t]{3}{*}{ Maternal education } & Illiterate & Reference & \\
\hline & & Primary & $0.00(-0.14,0.14)$ & 0.977 \\
\hline & & Secondary+ & $0.69(0.23,1.16)$ & $0.004^{*}$ \\
\hline \multirow[t]{8}{*}{ Model $2^{a}$} & \multirow[t]{2}{*}{ Water source } & Unimproved & Reference & \multirow[t]{2}{*}{0.846} \\
\hline & & Improved & $0.01(-0.12,0.14)$ & \\
\hline & \multirow[t]{2}{*}{ Maternal BMI $\left(\mathrm{kg} / \mathrm{m}^{2}\right)$} & $<18.5$ & Reference & \multirow[t]{2}{*}{0.744} \\
\hline & & $\geq 18.5$ & $0.02(-0.12,0.17)$ & \\
\hline & \multirow[t]{2}{*}{ Maternal anemia } & Anemic & Reference & \multirow[t]{2}{*}{$<0.001^{*}$} \\
\hline & & Not anemic & $0.40(0.26,0.53)$ & \\
\hline & \multirow[t]{2}{*}{ Antenatal care visits } & $<4$ & Reference & \multirow[t]{2}{*}{0.567} \\
\hline & & $\geq 4$ & $0.05(-0.11,0.20)$ & \\
\hline \multirow[t]{23}{*}{ Model $3^{b}$} & \multirow[t]{2}{*}{ Child sex } & Boy & Reference & \multirow[t]{2}{*}{$0.019^{*}$} \\
\hline & & Girl & $0.16(0.03,0.30)$ & \\
\hline & \multirow[t]{2}{*}{ Child age (months) } & $<12$ & $0.72(0.57,0.88)$ & \multirow[t]{2}{*}{$<0.001$} \\
\hline & & $12-23$ & Reference & \\
\hline & \multirow[t]{3}{*}{ Birth size } & Small & Reference & \\
\hline & & Average & $0.25(0.08,0.42)$ & $0.003^{*}$ \\
\hline & & Large & $0.15(-0.03,0.33)$ & 0.093 \\
\hline & \multirow[t]{2}{*}{ Height-for-age } & $<-2$ Z-score & Reference & \multirow[t]{2}{*}{0.630} \\
\hline & & $\geq-2$ Z-score & $0.04(-0.13,0.21)$ & \\
\hline & \multirow[t]{2}{*}{ Weight-for-age } & $<-2$ Z-score & Reference & \multirow[t]{2}{*}{$0.031^{*}$} \\
\hline & & $\geq-2$ Z-score & $0.22(0.02,0.42)$ & \\
\hline & Weight-for-height & $<-2$ Z-score & Reference & 0.438 \\
\hline & & $\geq-2$ Z-score & $0.09(-0.13,0.30)$ & \\
\hline & Infection ${ }^{c}$ & No & $0.18(0.02,0.33)$ & $0.025^{*}$ \\
\hline & & Yes & Reference & \\
\hline & Currently breastfeeding & No & Reference & $0.002^{*}$ \\
\hline & & Yes & $0.28(0.12,0.44)$ & \\
\hline & Vitamin A supplement & No & Reference & $0.021^{*}$ \\
\hline & & Yes & $0.17(0.06,0.28)$ & \\
\hline & $\mathrm{MDD}^{\mathrm{d}}$ & No & Reference & 0.701 \\
\hline & & Yes & $0.04(-0.16,0.24)$ & \\
\hline & $\mathrm{MMF}^{\mathrm{e}}$ & No & Reference & $0.034^{*}$ \\
\hline & & Yes & $0.11(0.05,0.16)$ & \\
\hline
\end{tabular}

${ }^{a}$ Model 2: adjusted for region, wealth category, and maternal education level

${ }^{\mathrm{b}}$ Model 3: adjusted for region, wealth category, maternal education level, and maternal anemia

Infection defined as (yes, any one of history of cough, diarrhea or fever in the last two weeks preceding the survey)

${ }^{d}$ MDD: Minimum dietary diversity (yes) when a child ate from four or more food groups

eMMF: Minimum meal frequency (yes) when a child ate at least three and four times a day for breastfeeding and non-breastfeeding

children, respectively 
the reports of previous studies [13,20]. Breast milk is the main source of nutrients during the early stages of life. Thus, the association of maternal anemia with the $\mathrm{Hb}$ level of the child could be, in part, due to the low nutrients content of the breast milk of anemic mothers [21].

Weight-for-age was significantly associated with $\mathrm{Hb}$ level independent of other factors. The mean $\mathrm{Hb}$ of children who were not underweight (weight-for-age $\geq-2$ Z-score) was significantly higher, compared with that of underweight children. Compared with children of low birth weight (small birth size), children of average birth size demonstrated a higher mean $\mathrm{Hb}$ level. Previous studies also found child undernutrition associated with anemia $[5,20]$. No history of infection, as measured by no cough or fever in the last two weeks prior to the survey, was associated with a significantly higher mean $\mathrm{Hb}$ level. The result was in concordance with other studies which reported higher risks of anemia or undernutrition to be associated with infection [5, 22-24].

In this study, iron supplementation and deworming did not demonstrate significant associations with $\mathrm{Hb}$ level. At first glance, our findings might appear to conflict with public health recommendations [3, 4]. Iron is essential for the production of red blood cells [3, 21] and $\mathrm{Hb}$ level could be presumed to be higher in children who took iron supplements. However, some studies have shown that micronutrient interventions are less effective unless implemented in an integrated approach $[25,26]$. The lack of association between these micronutrient interventions and $\mathrm{Hb}$ level could be due to some possible reasons like 1) in the DHS program, dose, frequency, and adherence to these interventions were not assessed, albeit they were reported to influence $\mathrm{Hb}$ responses to anemia prevention and control interventions [24, 25, 27]. Thus, the lack of accounting for these factors might have influenced our results, 2) the children on the micronutrient supplementations might be the ones who were already anemic and did not yet recover from the state of deficiency, $3)$ the high level of multiple micronutrient deficiency in Ethiopia [28, 29] could also have influenced the $\mathrm{Hb}$ response to iron supplementation as reported by a study in Mexico [25], or 4) it could be due to statistical power inadequacy because the data showed that only a small number of children took the iron supplement as well as the deworming medications.

Our finding was in concordance with previous reports that showed $\mathrm{Hb}$ level to be influenced by multiple factors, originating from individual, household, and community levels $[5,10]$. Prevention of childhood anemia remains among the major public health agendas in most of the developing countries [1], including Ethiopia [11]. The WHO has outlined essential public health and nutrition interventions to reduce the burden of childhood anemia [3, 21]. Most of the WHO anemia prevention and control recommendations have been incorporated in the Ethiopians National Nutrition Programs and Strategies [11], albeit the implementation has been sub-optimal, fragmented, and mainly focused on addressing the immediate causes $[2,11]$. Thus, it stands important for policy makers in Ethiopia to enhance the implementation of the existing anemia prevention and control interventions in a multi-sectoral and comprehensive approach. The determinants of $\mathrm{Hb}$ level, particularly the contextual factors, vary significantly across geographical regions. The relative contribution of the determinants to the burden of anemia is also contextual [6]. For example, recent reports have shown that the contribution of iron deficiency to the burden of anemia in developing countries is not as high as the widely held presumption that it accounts for almost $50 \%$ of the anemia burden [6]. Thus, it is worthy of conducting further studies considering the geospatial variations in determinants of $\mathrm{Hb}$ level and also design locally sensitive interventions.

One of the strengths of this study was the use of a nationally representative sample and objectively measured biomarkers: $\mathrm{Hb}$ level, weight, and height. The use of multilevel analysis scheme which took into account the hierarchical nature of the relationships among the various influences of $\mathrm{Hb}$ level might have avoided the nullifying effect of the intermediate factors on the association of the distal factors and $\mathrm{Hb}$ level. The inclusion of various explanatory factors (child, maternal, and household variables) might have improved the comprehensiveness of the study and enabled adjustment for various potential confounding variables. However, this study has important limitations. First, the design of the study, cross-sectional, precludes establishing temporal relations and making causal inferences. Second, the collection of data on some of the variables based on respondents' memory of past events might have introduced recall bias. Third, the lack of data on intestinal helminths, reported to influence $\mathrm{Hb}$ level, could be another limitation of this study. Fourth, we did not consider hereditary anemias in the study due to the lack of data in the dataset we used. However, it is less likely that our findings were affected by the lack of inclusion of hereditary anemias because the incidence of hereditary anemias is generally low in Ethiopia [30]. Fifth, we did not account for the effects of dose, duration, and adherence of deworming, iron, and vitamin A supplementation, which might have biased our findings. Despite these limitations, we believe the findings of this study could serve as evidence basis for further studies on the determinants of $\mathrm{Hb}$ level of children in Ethiopia. 


\section{Conclusion}

$\mathrm{Hb}$ level of infants and young children in Ethiopia was found to be influenced by various household, maternal and child related factors. Designing and scaling up comprehensive nutrition interventions, with due emphasis on the multifactorial nature of $\mathrm{Hb}$, may represent a potential consideration to reduce the burden of anemia in Ethiopia.

\section{Abbreviations}

ANC: Antenatal care; a $\beta$ : Adjusted $\beta$; BMI: Body mass index; Cl: Confidence interval; DHS: Demographic and health surveys; EDHS: Ethiopian demographic and health survey; Hb: Hemoglobin; MDD: Minimum dietary diversity; MMF: Minimum meal frequency; SD: Standard deviation; USAID: United States Agency for International Development; WHO: World Health Organization

\section{Acknowledgments}

We acknowledge the USAID/MEASURE DHS Program for their permission to access the dataset and Tehran University of Medical Sciences-International Campus.

\section{Funding}

This research received no specific grant from any funding agency in public, commercial or not-for-profit sectors.

\section{Availability of data and materials}

The full dataset of EDHS 2016 is publicly available and freely accessible on the DHS program website: http://dhsprogram.com/data/dataset/Ethiopia_ Standard-DHS_2016.cfm. The DHS program is authorized to provide access to the dataset. Interested researchers can access and use the data, at no cost, upon registration on the program website: https://dhsprogram.com/ data/new-user-registration.cfm.

\section{Authors' contributions}

SHM and AE conceived and led the study. SHM extracted the data set, prepared the analysis plan, performed the data analysis, and wrote the manuscript. TDH participated in the extraction of dataset, and interpretation of findings. AE supervised the work and reviewed the work critically. All authors reviewed and approved the final manuscript.

\section{Ethics approval and consent to participate}

This study was done based on an existing and publicly available dataset, EDHS 2016. The Institutional Review Boards (IRB) of Ethiopian Public Health Institute and ICF International approved the survey protocol of EDHS 2016. Caregivers of the study participants provided informed written consent of participation in the study. For this particular work, approval to access the dataset was obtained from the USAID/DHS Program. Additional ethical approval was also obtained from the IRB of Tehran University of Medical Sciences, Ref.No: IR.TUMS.VCR.REC.1397.142

\section{Consent for publication}

Not applicable.

\section{Competing interests}

The authors declare that they have no competing interests.

\section{Publisher's Note}

Springer Nature remains neutral with regard to jurisdictional claims in published maps and institutional affiliations.

\section{Author details}

${ }^{1}$ Department of Community Nutrition, School of Nutritional Sciences and Dietetics, Tehran University of Medical Sciences-International Campus, Tehran, Iran. ${ }^{2}$ Department of Epidemiology, University Medical Center Groningen, University of Groningen, Groningen, The Netherlands. ${ }^{3}$ Obesity and Eating Habits Research Center, Endocrinology and Metabolism Molecular Cellular Sciences Institute, Tehran University of Medical Sciences, Tehran, Iran.
${ }^{4}$ Department of Community Nutrition, School of Nutritional Sciences and Dietetics, Tehran University of Medical Sciences, Tehran, Iran. ${ }^{5}$ Food Security Research Center, Department of Community Nutrition, Isfahan University of Medical Sciences, Isfahan, Iran.

Received: 11 December 2018 Accepted: 31 March 2019

Published online: 15 April 2019

\section{References}

1. Kassebaum NJ, Jasrasaria R, Naghavi M, Wulf SK, Johns N, Lozano R, et al. A systematic analysis of global anemia burden from 1990 to 2010. Blood. 2014;123:615-24.

2. Central Statistical Agency [Ethiopia] and ICF International. Ethiopia Demographic and Health Survey 2016. https://dhsprogram.com/pubs/pdf/ FR328/FR328.pdf. Accessed 17 Mar 2019.

3. World Health Organization. Iron deficiency anaemia: assessment, prevention and control: a guide for programme managers. World Health Organization; 2001. http://apps.who.int/iris/handle/10665/66914. Accessed 17 Mar 2019.

4. Lopez A, Cacoub P, Macdougall IC, Peyrin-Biroulet L. Iron deficiency anaemia. Lancet. 2016;387:907-16.

5. Allali S, Brousse V, Sacri AS, Chalumeau M, de Montalembert M. Anemia in children: prevalence, causes, diagnostic work-up, and long-term consequences. Expert Rev Hematol. 2017;10:1023-8.

6. Petry N, Olofin I, Hurrell RF, Boy E, Wirth JP, Moursi M, et al. The proportion of Anemia associated with Iron deficiency in low, medium, and high human development index countries: a systematic analysis of National Surveys. Nutrients. 2016;8(11):693-709.

7. Liu J, Sun B, Yin H, Liu S. Hepcidin. A promising therapeutic target for Iron disorders: a systematic review. Medicine (Baltimore). 2016;95:e3150.

8. Muchie KF. Determinants of severity levels of anemia among children aged 6-59 months in Ethiopia: further analysis of the 2011 Ethiopian demographic and health survey. BMC Nutrition. 2016;2:51.

9. Mohammed SH, Taye H, Sissay TA, Larijani B, Esmaillzadeh A. Teff consumption and anemia in pregnant Ethiopian women: a case-control study. Eur J Nutr. 2018:57:1-8.

10. Smith LC, Haddad L. Reducing child undernutrition: past drivers and priorities for the post-MDG era. World Dev. 2015;68:180-204.

11. Lemma F, Matji J. Delivery platforms for sustained nutrition in Ethiopia. Lancet. 2013;382:488-9.

12. Gutema B, Adissu W, Asress Y, Gedefaw L. Anemia and associated factors among school-age children in Filtu town, Somali region, Southeast Ethiopia. BMC Hematology. 2014;14:13.

13. Gebreegziabiher G, Etana B, Niggusie D. Determinants of Anemia among children aged 6-59 months living in Kilte Awulaelo Woreda, Northern Ethiopia. Anemia. 2014;2014:245870.

14. Victora CG, Huttly SR, Fuchs SC, Olinto MT. The role of conceptual frameworks in epidemiological analysis: a hierarchical approach. Int J Epidemiol. 1997;26:224-7.

15. Altman DG, Royston P. The cost of dichotomising continuous variables. BMJ. 2006:332:1080.

16. Short Fabic M, Choi Y, Bird S. A systematic review of demographic and health surveys: data availability and utilization for research. Bull World Health Organ. 2012;90:604-12.

17. Group WHOMGRS. WHO child growth standards based on length/height, weight and age. Acta Paediatr Suppl. 2006;450:76-85.

18. World Health Organization. Indicators for assessing infant and young child feeding practices part 3: country profiles. 2010. http://www.who.int/ nutrition/publications/infantfeeding/9789241599757/en/. Accessed 17 Mar 2019

19. Jima D, Getachew A, Bilak H, Steketee RW, Emerson PM, Graves PM, et al. Malaria indicator survey 2007, Ethiopia: coverage and use of major malaria prevention and control interventions. Malar J. 2010;9:58.

20. Khan JR, Awan N, Misu F. Determinants of anemia among 6-59 months aged children in Bangladesh: evidence from nationally representative data. BMC Pediatr. 2016;16(3):1-12.

21. World Health Organization. Essential nutrition actions: improving maternal, newborn, infant and young child health and nutrition. 2013. http://www. who.int/nutrition/publications/infantfeeding/essential_nutrition_actions/en/. Accessed 17 Mar 2019.

22. Ballin A, Senecky Y, Rubinstein U, Schaefer E, Peri R, et al. Anemia associated with acute infection in children. Isr Med Assoc J. 2012;14:484-7. 
23. Asfaw M, Wondaferash M, Taha M, Dube L. Prevalence of undernutrition and associated factors among children aged between six to fifty nine months in Bule Hora district, South Ethiopia. BMC Public Health. 2015;15:41.

24. Mohammed SH, Esmaillzadeh A. The relationships among iron supplement use, $\mathrm{Hb}$ concentration and linear growth in young children: Ethiopian demographic and health survey. $\mathrm{Br} J$ Nutr. 2017;118:730-6.

25. Allen LH, Rosado JL, Casterline JE, Lopez P, Munoz E, Garcia OP, et al. Lack of hemoglobin response to iron supplementation in anemic mexican preschoolers with multiple micronutrient deficiencies. Am J Clin Nutr. 2000;71:1485-94.

26. Hieu NT, Sandalinas F, de Sesmaisons A, Laillou A, Tam NP, Khan NC, et al. Multi-micronutrient-fortified biscuits decreased the prevalence of anaemia and improved iron status, whereas weekly iron supplementation only improved iron status in Vietnamese school children. Br J Nutr. 2012:108:1419-27.

27. Bilenko $N$, Yehiel M, Inbar Y, Gazala E. The association between anemia in infants, and maternal knowledge and adherence to iron supplementation in southern Israel. Isr Med Assoc J. 2007;9:521-4.

28. Herrador Z, Sordo L, Gadisa E, Buno A, Gomez-Rioja R, Iturzaeta JM, et al. Micronutrient deficiencies and related factors in school-aged children in Ethiopia: a cross-sectional study in Libo Kemkem and Fogera districts, Amhara regional state. PLoS One. 2014;9(12):e112858.

29. Amare B, Moges B, Fantahun B, Tafess K, Woldeyohannes D, Yismaw G, et al. Micronutrient levels and nutritional status of school children living in Northwest Ethiopia. Nutr J. 2012;11:108.

30. Deribew A, Tessema GA, Deribe K, Melaku YA, Lakew Y, Amare AT, et al. Trends, causes, and risk factors of mortality among children under 5 in Ethiopia, 1990-2013: findings from the global burden of disease study 2013. Popul Health Metrics. 2016;14(1):42.

Ready to submit your research? Choose BMC and benefit from:

- fast, convenient online submission

- thorough peer review by experienced researchers in your field

- rapid publication on acceptance

- support for research data, including large and complex data types

- gold Open Access which fosters wider collaboration and increased citations

- maximum visibility for your research: over $100 \mathrm{M}$ website views per year

At $\mathrm{BMC}$, research is always in progress.

Learn more biomedcentral.com/submissions 